\title{
ANALYSIS OF THE EFFECTS OF AGEING ON THE COHESIVE STRENGTH OF POLYMER-MODIFIED BITUMEN AT LOW TEMPERATURES
}

\author{
Chuanfeng ZHENG ${ }^{1}$, Genze $\mathrm{LI}^{2}$, Yazhi XU ${ }^{3^{*}}$, Danni WANG ${ }^{4}$, Dan $\mathrm{LV}^{5}$ \\ 1, 2, 3, ${ }^{5}$ College of Construction Engineering, Jilin University, Changchun, China \\ ${ }^{4}$ College of Traffic, Jilin University, Changchun, China
}

Received 25 October 2017; accepted 14 March 2018

\begin{abstract}
The decay law on the ageing process of the cohesive strength of styrene-butadiene-styrene(SBS)- and polyethylene(PE)-modified bitumens at low temperatures was investigated. The rotated-thin-film oven test was used to age the two types of polymer-modified bitumens. The cohesive strengths at different low-temperature conditions were tested quantitatively according to technology for testing the low-temperature cohesive strength of bitumen. The decay curve of bitumen low-temperature cohesive strengths was drawn, and the embrittlement time of bitumen at different ageing states was obtained according to the decay curve. Results showed that ageing time definitely influenced the attenuation degree of the low-temperature cohesive strength of the two types of polymer-modified bitumens and influenced the appearance of the low-temperature cohesive strength peak, i.e., the bitumen embrittlement time, which advanced after ageing. The lightweight components of polymer-modified bitumen were lost after ageing. The bitumen embrittlement time was advanced, and the sharp attenuation of the low-temperature cohesive strength of bitumen appeared. In the future, bitumen antiageing technology and lighter part pre-supplement technology should be studied in-depth.
\end{abstract}

Keywords: ageing, bitumen embrittlement time, decay curve, low-temperature cohesive strength, polymer-modified bitumen.

\section{Introduction}

Bitumen mixture naturally cracks and loosens when the aggregate-bitumen and mineral separate into two failure modes. The first mode is the separation between the bitumen and mineral aggregates and is called adhesion failure destruction. The second mode is the cracking of the bitumen mortar itself and is called cohesion failure destruction. These two types of failure modes are associated with temperature, oil film thickness, bitumen quality, mineral aggregate surface property and contact surface loading mode and commonly occur in the failure process of mixtures (Arifuzzaman \& Hassan, 2014; Falchetto, Moon, \& Wistuba, 2016; Guo, Tan \& Zhou, 2014; Zheng, Zhao, \& Xiang, 2012; Zheng, Chen, \& Zhao, 2014). Therefore, when improving the low-temperature cohesive strength of bituminous binders is necessary to enhance the anticracking and anti-loose ability of mixtures.

In the process of asphalt mixture preparation, transportation, paving and long-term road use, bitumen is aged by the external environmental effects of heat, oxygen and light. The lightweight components of bitumen, which are aromatics and saturates, are lost during the ageing process (Kim, Lee, Amirkhanian, 2013; Y. T. Li \& L.F. Li, \& Zhang, 2010; Yut \& Zofka, 2014; Zhu, Zhou, \& Wang, 2014). Furthermore, the proportion of asphaltenes and resins increases, thus making bitumen hard and brittle. The conventional bitumen test is always used in traditional research to check and analyse bitumen ageing, such as penetration, ductility, softening point, high-temperature viscosity and DSR. However, these factors cannot accurately chek low-temperature performance, and the effects of ageing on the pavement performance of mixtures are estimated indirectly by traditional research, thus yielding limited results for analysing low-temperature asphalt mixture damage (Forough, Nejad \& Khodaii, 2017; Krcmarik, Vama \& Kutay, 2016; Lopes, Zhao, \& Chailleux, 2014; Mills-Beale, You, \& Fini, 2014; Wang, Long, \& Shen, 2014; Zhu et al., 2014).

In the last two years, researchers have proposed that cohesive strength should be used as a strength index of bituminous-binder cohesive low-temperature performances. Cohesive strength is an vital mechanic index on the bitumen-mineral aggregate contact surface because it

*Corresponding author. E-mail: xuyazhi00@163.com 
can effectively estimate asphalt mixture low-temperature pavement performances. Our team developed a quantitative testing technology for bituminous binder low-temperature cohesive strength to conduct further relevant research. After obtaining the Chinese invention patent authorization, this technology provided a sufficient experimental basis for relevant follow-up study (Lv, Zheng, \& Qin, 2014; Yeon, Kim, \& Lee, 2014; Zheng, Zhao, \& Chen, 2013).

Literature shows that asphalt mixture low-temperature pavement performances, particularly the low-temperature anti-cracking anti-loosing ability, manifest different degrees of decline after ageing. The proposed bituminous binder low-temperature cohesive strength index provides an opportunity for analysing the effect of ageing on pavement performance (Cerni, Cardone, \& Colagrande, 2011; Hampl, Vacin, \& Jasso, 2015; Hamzah, Yee, \& Golchin, 2017; Jahanbakahsh, Karimi \& Tabatabaee, 2017). In this study, the low-temperature cohesive strengths of SBS- and PE-modified bitumens at different low temperatures and different ageing times were tested by using the quantitative testing technology, and the decay curve of bitumen lowtemperature cohesive strength was drawn. How ageing influences the bitumen low-temperature cohesive strength and the mixture low-temperature pavement performance was analysed.

\section{Test}

\subsection{SBS-and PE-modified bitumen technical parameters}

SBS-modified bitumen is a styrene type thermoplastic elastomer, which is a styrene-butadiene-styrene triblock copolymer. The two-phase structure clearly shows the polystyrene and polybutadiene chains in the SBS-modified bitumen. Polybutadiene is the continuous phase, because polystyrene is the dispersed phase. The two-phase separation structure forms a 3D space network structure with the bitumen matrix and becomes an SBS-modified bitumen after the three preparation processes, namely, swelling, cutting and developing. Thus, this structure effectively improves bitumen temperature performance, tensile property, elasticity, cohesive adhesion property, mixture stability and ageing resistance (Gao, Zhang \& Zhang, 2002; Wang, Zhang \& Zhang, 2003; Wang, Liu, \& Li, 2006). Styrene-Butadiene-Styrene-modified bitumen is the most used variety of bitumen in research and applications because it can simultaneously improve bitumens in high and low temperatures and because it is sensitive to temperature.
Polyethylene-modified bitumen manifests good performance about flexibility, elongation and impact resistance. It also has a great molecular weight (up to 300,000), belongs to linear long-chain molecular structure, and becomes a multi-branched dendritic structure owing to many alkyl side chains, and methyl-branched chains. The viscosity of the bitumen can be significantly increased becausethe multiple branches and an irregular molecular structure exists; the adhesion between the modified bitumen and aggregate can also be improved (Fang, Li, \& Zhang, 2008; Fang, M. R. Zhang, \& Z. P. Zhang, 2009; Fang, Hu, \& Zhou, 2011). Both SBS and PE are mixed with the bitumen in an amount of 5 percent (Modarres, 2013; Nejad, Azarhoosh, \& Hamedi, 2014; Zhao, Gu \& $\mathrm{Xu}, 2010)$. The technical limits of SBS- and PE-modified bitumen in this study are shown in Table 1 .

\subsection{Polymer-modified bitumen ageing simulation}

Bituminous binder indoor ageing was tested by the rotatingthe-film heating test used in bitumen rotary film heating oven. The test temperature in the oven was $163 \pm 0.5^{\circ} \mathrm{C}$, the flow of air was $4000 \mathrm{ml} / \mathrm{min} \pm 200 \mathrm{ml} / \mathrm{min}$, and the fan speed in the oven was $1725 \mathrm{r} / \mathrm{min}$ to make sure that the air inside is sufficiently and uniformly heated. The oven was preheated $16 \mathrm{~h}$ before the test. The bitumen mass in each sample vial was $35 \mathrm{~g} \pm 0.5 \mathrm{~g}$ when the samples were ready. The ageing times in this test were $0 \mathrm{~h}, 6 \mathrm{~h}, 18 \mathrm{~h}, 24 \mathrm{~h}$ and $48 \mathrm{~h}$ to analyse the effects of the ageing process on the cohesive strength of the bituminous binder at low temperatures.

\subsection{Quantitative test of bituminous binder tensile cohesive strength at low temperatures}

The study found that both the cohesion failure and adhesion failure always appeared simultaneously in the presence of thin oil films on the mineral aggregate contact surface. The conventional failure mode on the mineral aggregate contact surface is shown in Figure 1. The relationship among bituminous binder cohesive strength, adhesion strength and tensile failure load is shown in Eq. (1).

$$
R_{a} S_{a}+R_{c} S_{c}=F,
$$

where $R_{a}$ - the adhesion strength of the bituminous binder at low temperatures, MPa; $S_{a}$ - the adhesion failure zone area of the mineral aggregate contact surface, $\mathrm{m}^{2}$; $R_{c}$ - the cohesive strength of the bituminous binder at low temperatures, MPa; $S_{c}$ - the cohesion failure zone area of the mineral aggregate contact surface, $\mathrm{m}^{2}$.

Table 1. Technical limits of SBS- and PE-modified bitumen

\begin{tabular}{|c|c|c|c|c|c|c|}
\hline \multirow{2}{*}{ Bitumen species } & \multicolumn{2}{|c|}{ Penetration $/ 0.1 \mathrm{~mm}$} & \multirow{2}{*}{$15{ }^{\circ} \mathrm{C}$ ductility $/ \mathrm{cm}$} & \multirow{2}{*}{ Softening Point $/{ }^{\circ} \mathrm{C}$} & \multicolumn{2}{|c|}{ Standard Viscosity/pa.s } \\
\cline { 2 - 3 } & $5{ }^{\circ} \mathrm{C}$ & $25{ }^{\circ} \mathrm{C}$ & & & $60{ }^{\circ} \mathrm{C}$ & $90{ }^{\circ} \mathrm{C}$ \\
\hline SBS-modified bitumen & 7.5 & 97.2 & $>15$ & 44.7 & 6246 & 3820 \\
\hline PE-modified bitumen & 7.0 & 92.1 & $>15$ & 45.3 & 6574 & 4029 \\
\hline
\end{tabular}




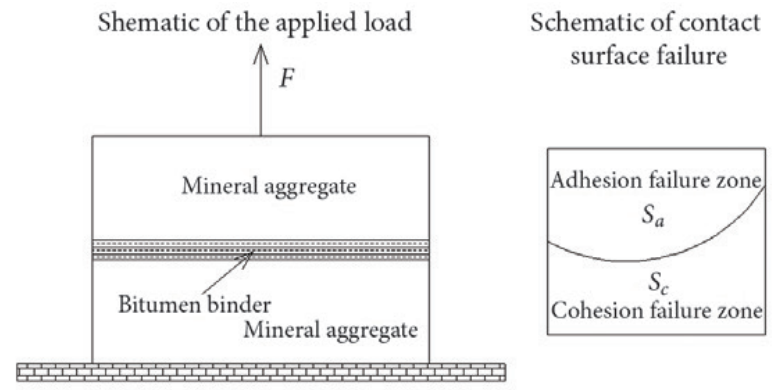

Figure 1. Schematic of the tension failure test of the mineral aggregate contact surface

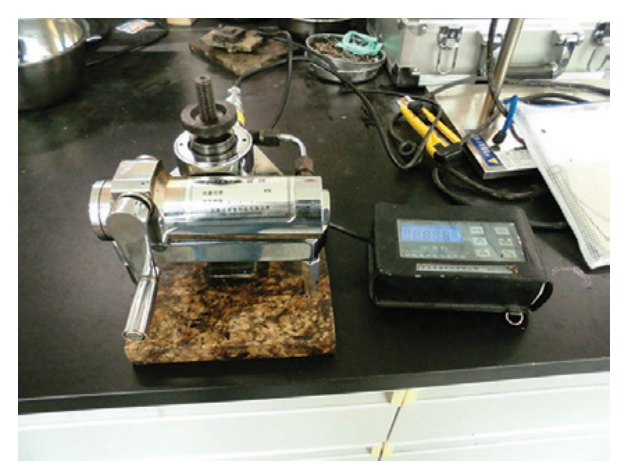

Figure 2. HC-40 hydraulic force measuring device

Cohesion failure damage on the mineral aggregate contact surface was observed where thick oil films on the mineral aggregate contact surface exists. At this point, the relationship between the cohesive strength of the bituminous binder at low temperatures and the tensile failure load was $R_{c} S_{c}=F$; the meaning of the limits in this formula are similar to those in Eq. (1). In this case, the bituminous binder low-temperature cohesion strength at different states (e.g., different ageing state, different temperatures) could be obtained on the basis of the relationship between the tensile failure load and the area of the mineral aggregate contact surface by preparing the mineral-aggregate contact surface test pieces, which have uniform bitumen film thickness. The test pieces were prepared with an oil film thickness of $0.25 \mathrm{~mm}$. The size of the specimen surface is $1.5 \times 1.5 \mathrm{~cm}$. The bituminous binder low-temperature cohesive strength was tested at different temperatures (i.e., $-5{ }^{\circ} \mathrm{C},-10{ }^{\circ} \mathrm{C},-15^{\circ} \mathrm{C},-20^{\circ} \mathrm{C}$ and $-25^{\circ} \mathrm{C}$ ) and different ageing times (i.e., $0 \mathrm{~h}, 6 \mathrm{~h}, 18 \mathrm{~h}$, $24 \mathrm{~h}$ and $48 \mathrm{~h}$ ). The test equipment is shown in Figure 2, and the test process is shown in Figure 3.

\section{Test results and discussion}

\subsection{Test results on the low-temperature cohesive strength of SBS- and PE-modified bitumen}

The low-temperature cohesive strengths of the two types of polymer-modified bitumens were tested in this research at different ageing statuses and different temperatures by using the abovementioned test methods. The amount of test sample during the testing process was increased to
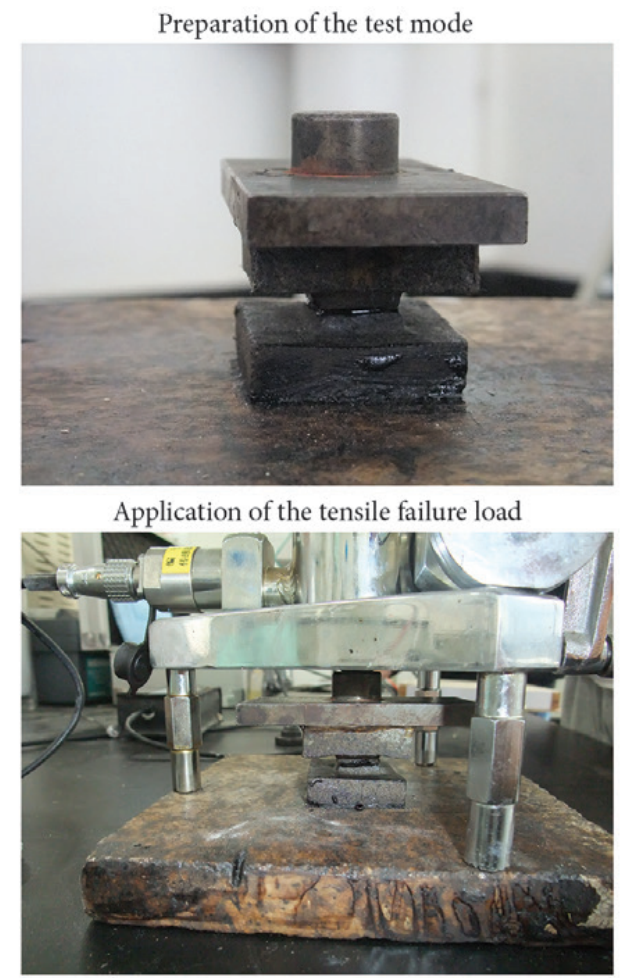

Material aggregate contact sudrface after tensile failure

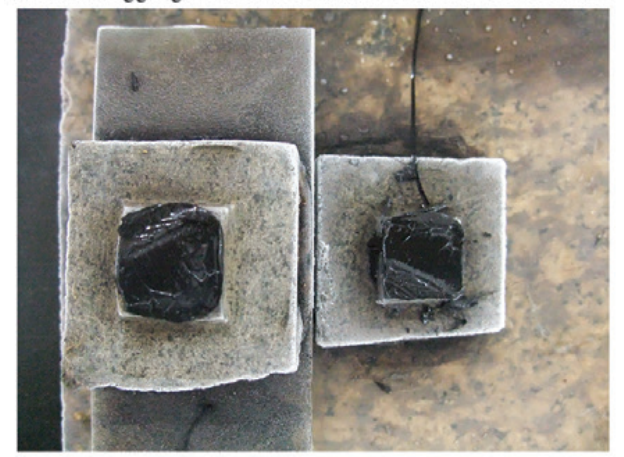

Figure 3. Quantitative test for the low-temperature cohesive strength of bitumen

improve the accuracy of the test and the reliability of the test results. Each test consisted of 12 parallel trials. The average data after excluding individual large discrete data were obtained. The test results of the cohesive strengths of the two polymer-modified bitumen at low temperatures are shown in Tables 2 and 3.

\subsection{Effects of ageing on the cohesive strength values of bitumen at low temperatures}

The effects of ageing on bitumen low-temperature cohesive strength at different temperature conditions are shown in Figures 4, 5, 6, 7 and 8. Bitumen is a temperature-sensitive material and has necessary mechanical parameters that often manifest essential relationships with temperature. Therefore, the correlation analysis of the effects of ageing should be combined with the temperature reason. Bituminous binder low-temperature cohesive strength was enhanced by the ageing effect at $-5^{\circ} \mathrm{C}$ 
Table 2. Test results of the low-temperature cohesive strength of the SBS-modified bitumen at different ageing states

\begin{tabular}{|c|c|c|c|}
\hline $\begin{array}{l}\text { Bitumen } \\
\text { ageing state }\end{array}$ & $\begin{array}{c}\text { Temperature, } \\
{ }^{\circ} \mathrm{C}\end{array}$ & $\begin{array}{l}\text { Tensile failure } \\
\text { load, kN }\end{array}$ & $\begin{array}{l}\text { Tensile cohesive } \\
\text { strength, } \mathrm{MPa}\end{array}$ \\
\hline \multirow{5}{*}{$0 \mathrm{~h}$} & -5 & 0.28 & 1.25 \\
\hline & -10 & 0.45 & 2.00 \\
\hline & -15 & 0.50 & 2.22 \\
\hline & -20 & 0.33 & 1.45 \\
\hline & -25 & 0.22 & 0.97 \\
\hline \multirow{5}{*}{$6 \mathrm{~h}$} & -5 & 0.32 & 1.44 \\
\hline & -10 & 0.43 & 1.92 \\
\hline & -15 & 0.45 & 1.98 \\
\hline & -20 & 0.27 & 1.20 \\
\hline & -25 & 0.20 & 0.90 \\
\hline \multirow{5}{*}{$18 \mathrm{~h}$} & -5 & 0.37 & 1.64 \\
\hline & -10 & 0.42 & 1.87 \\
\hline & -15 & 0.28 & 1.23 \\
\hline & -20 & 0.21 & 0.92 \\
\hline & -25 & 0.16 & 0.69 \\
\hline \multirow{5}{*}{$24 \mathrm{~h}$} & -5 & 0.41 & 1.83 \\
\hline & -10 & 0.42 & 1.85 \\
\hline & -15 & 0.24 & 1.07 \\
\hline & -20 & 0.18 & 0.82 \\
\hline & -25 & 0.12 & 0.55 \\
\hline \multirow{5}{*}{$48 \mathrm{~h}$} & -5 & 0.48 & 2.12 \\
\hline & -10 & 0.34 & 1.50 \\
\hline & -15 & 0.19 & 0.84 \\
\hline & -20 & 0.14 & 0.62 \\
\hline & -25 & 0.09 & 0.42 \\
\hline
\end{tabular}

such that the cohesive strength of the SBS-modified bitumen was $1.25 \mathrm{MPa}$ at $-5^{\circ} \mathrm{C}$; the cohesive strength was $1.64 \mathrm{MPa}$ after ageing for $18 \mathrm{~h}$ and $2.12 \mathrm{MPa}$ after $48 \mathrm{~h}$. However, the ageing effect caused the bitumen lowtemperature cohesive strength attenuated when the temperature ranged from $-5{ }^{\circ} \mathrm{C}$ to $-25^{\circ} \mathrm{C}$. The attenuation amplitude of the bituminous binder low-temperature cohesive strength was different at different low-temperature conditions. After ageing for $48 \mathrm{~h}$, the SBS-modified bitumen low-temperature cohesive strength attenuated by $25.0 \%, 62.2 \%, 57.2 \%$ and $56.7 \%$ at $-10{ }^{\circ} \mathrm{C},-15{ }^{\circ} \mathrm{C}$, $-20{ }^{\circ} \mathrm{C}$ and $-25{ }^{\circ} \mathrm{C}$, respectively. The PE-modified bitumen low-temperature cohesive strength attenuated by $23.7 \%, 67.9 \%, 69.6 \%$ and $69.2 \%$ at $-10{ }^{\circ} \mathrm{C},-15{ }^{\circ} \mathrm{C}$, $-20^{\circ} \mathrm{C}$ and $-25^{\circ} \mathrm{C}$, respectively. By this analysis, the ageing effect could increase the bituminous binder cohesive strength only at a small temperature range (e.g., from $0{ }^{\circ} \mathrm{C}$ to $-5{ }^{\circ} \mathrm{C}$ ). In most low-temperature environments, the ageing effect of the bituminous binder significantly effects the attenuation of the bituminous binder lowtemperature cohesive strength.
Table 3. Test results of the low-temperature cohesive strength of the PE-modified bitumen at different ageing states

\begin{tabular}{|c|c|c|c|}
\hline $\begin{array}{l}\text { Bitumen } \\
\text { ageing state }\end{array}$ & $\begin{array}{l}\text { Temperature, } \\
{ }^{\circ} \mathrm{C}\end{array}$ & $\begin{array}{l}\text { Tensile failure } \\
\text { load, } \mathrm{kN}\end{array}$ & $\begin{array}{l}\text { Tensile cohesive } \\
\text { strength, } \mathrm{MPa}\end{array}$ \\
\hline \multirow{5}{*}{$0 \mathrm{~h}$} & -5 & 0.37 & 1.64 \\
\hline & -10 & 0.47 & 2.07 \\
\hline & -15 & 0.48 & 2.14 \\
\hline & -20 & 0.30 & 1.35 \\
\hline & -25 & 0.20 & 0.89 \\
\hline \multirow{5}{*}{$6 \mathrm{~h}$} & -5 & 0.39 & 1.72 \\
\hline & -10 & 0.45 & 1.99 \\
\hline & -15 & 0.47 & 2.09 \\
\hline & -20 & 0.25 & 1.13 \\
\hline & -25 & 0.18 & 0.82 \\
\hline \multirow{5}{*}{$18 \mathrm{~h}$} & -5 & 0.40 & 1.79 \\
\hline & -10 & 0.44 & 1.97 \\
\hline & -15 & 0.22 & 0.99 \\
\hline & -20 & 0.16 & 0.72 \\
\hline & -25 & 0.14 & 0.62 \\
\hline \multirow{5}{*}{$24 \mathrm{~h}$} & -5 & 0.43 & 1.93 \\
\hline & -10 & 0.44 & 1.95 \\
\hline & -15 & 0.19 & 0.84 \\
\hline & -20 & 0.14 & 0.62 \\
\hline & -25 & 0.09 & 0.41 \\
\hline \multirow{5}{*}{$48 \mathrm{~h}$} & -5 & 0.48 & 2.15 \\
\hline & -10 & 0.36 & 1.58 \\
\hline & -15 & 0.15 & 0.69 \\
\hline & -20 & 0.09 & 0.41 \\
\hline & -25 & 0.06 & 0.27 \\
\hline
\end{tabular}

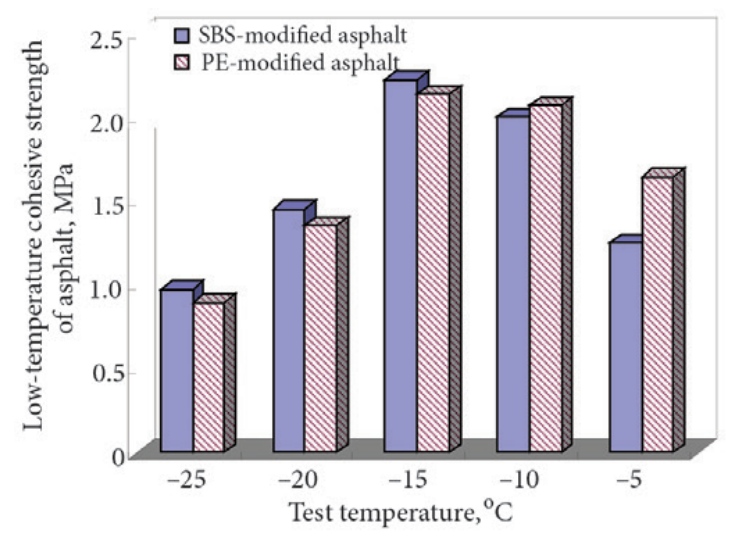

Figure 4. Change law of the two types of bitumen low-temperature cohesive strength after ageing for $0 \mathrm{~h}$

\subsection{Effects of ageing on the peak time of bitumen low-temperature cohesive strength}

According to the decay law of SBS- and PE-modified bitumen low-temperature cohesive strengths under the ageing and 


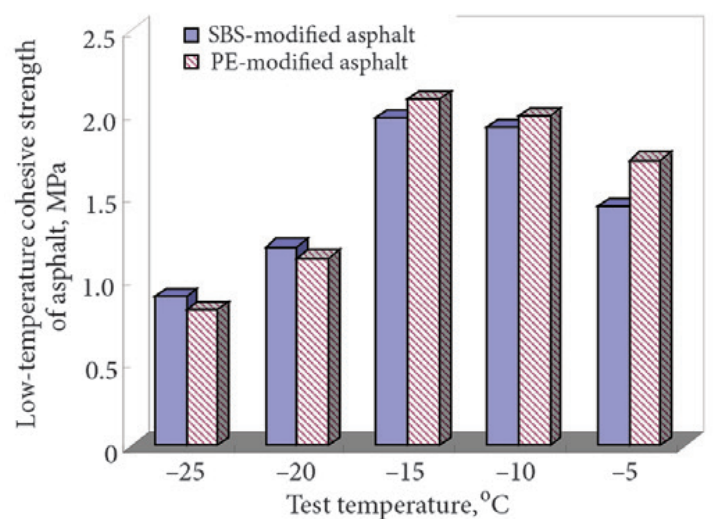

Figure 5. Change law of the two types of bitumen low-temperature cohesive strength after ageing for $6 \mathrm{~h}$

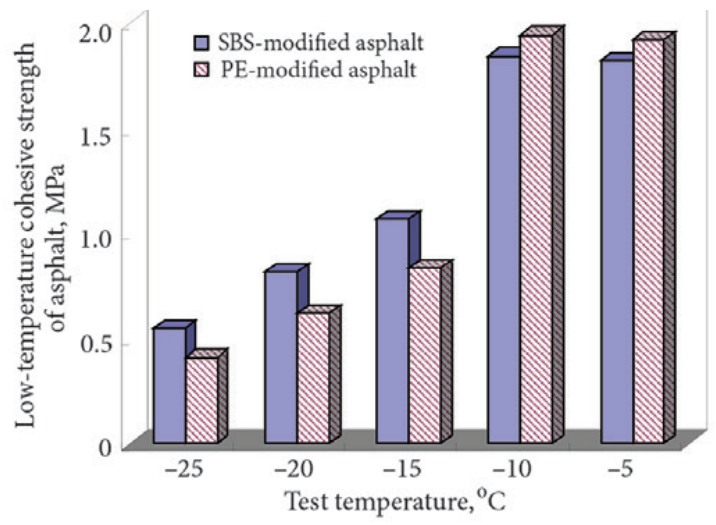

Figure 7. Change law of the two types of bitumen low-temperature cohesive strength after ageing for $24 \mathrm{~h}$

temperature coupling effects (Figures 9 and 10), the low-temperature cohesive strengths of the SBS- and PE-modified bitumens manifest differences at different temperature conditions. However, the decay law of the two low-temperature cohesive strength is fundamentally similar. Figures 9 and 10 show that the low-temperature cohesive strengths of the original and modified bitumens after ageing for $6 \mathrm{~h}$ peaks at $-15^{\circ} \mathrm{C}$ and $-10^{\circ} \mathrm{C}$ after ageing for $18 \mathrm{~h}$ and $24 \mathrm{~h}$. The low-temperature cohesive strength of the two types of bitumen presents a single attenuation trend with no peak after ageing for $48 \mathrm{~h}$.

The above analysis indicated that the ageing effect not only influenced the extent of the bituminous binder low-temperature cohesive strength but also gradually advanced the peak temperature time. The law in the figures

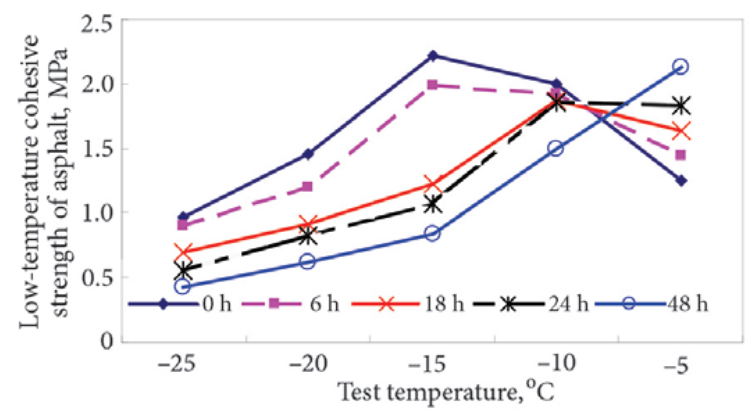

Figure 9. Influence of the ageing effects on the peak time of SBS-modified bitumen low-temperature cohesive strength

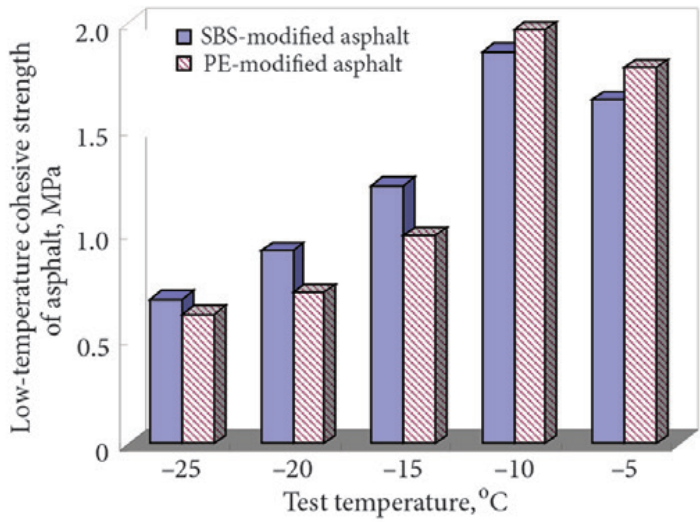

Figure 6. Change law of the two types of bitumen low-temperature cohesive strength after ageing for $18 \mathrm{~h}$

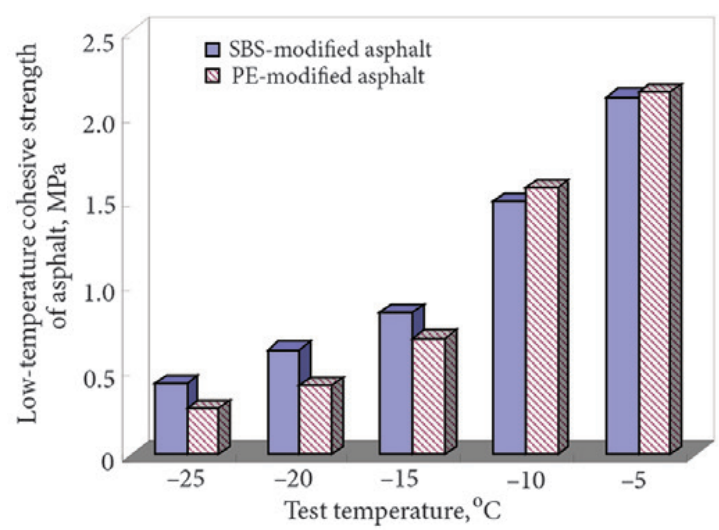

Figure 8. Change law of the two types of bitumen low-temperature cohesive strength after ageing for $48 \mathrm{~h}$

showed that bitumen low-temperature cohesive strength always decays rapidly after the bitumen cohesive strength peak occurs; thus, the bitumen low-temperature cohesive strength peak time is also considered the temperature time when bitumen material embrittlement occurs. The effects of the embrittlement temperature time on bitumen pavement performance at low temperatures were advanced and unfavourable. Binder low-temperature cohesive strength and mixture anti-cracking significantly decreased because of the embrittlement effects. This decrease was followed by low-temperature pavement damage. Thus, thow the ageing effect influences the bitumen embrittlement effects should be given enough attention when analysing the influence of the ageing effect on bitumen pavement performances.

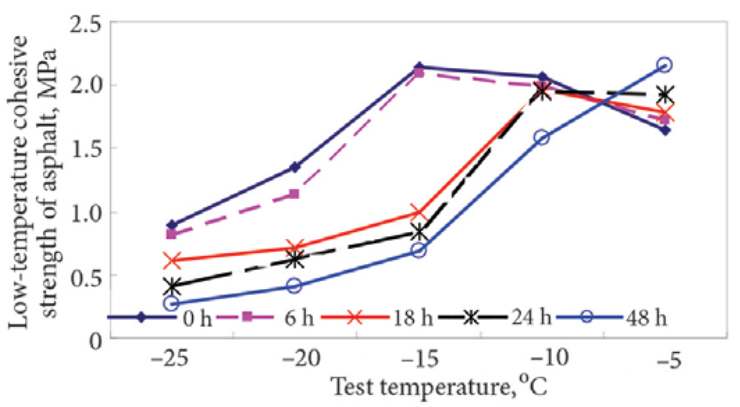

Figure 10. Influence of the ageing effects on the peak time of PE-modified bitumen low-temperature cohesive strength 


\subsection{The influence comparison between temperature and ageing time on bitumen cohesive strength}

In this paper, the test mainly determines the cohesive strength of two kinds of modified asphalt thick oil films under different low-temperature conditions and different ageing time. The grey system incidence theory is used to calculate the gray relational degree of ageing time and temperature (factors) on the cohesive strength of bitumen thick film (reference item). Let $X_{0}=\left\{X_{0}(1), X_{0}(2), \ldots, X_{0}\right.$ $(n)\}$ be the reference sequence. Let $X_{i}=X_{i}(1), X_{i}(2), \ldots$, $\left.X_{i}(n)\right\}$ be the comparison sequence. The series above will be processed according to Equations (2)-(5).

$$
\begin{gathered}
Y_{0}=\left\{Y_{0}(1), Y_{0}(2), Y_{0}(3), \ldots, Y_{0}(n)\right\}= \\
\left\{\frac{X_{0}(1)}{X_{0}}, \frac{X_{0}(2)}{\overline{X_{0}}}, \ldots, \frac{X_{0}(n)}{\overline{X_{0}}}\right\}, \\
\overline{X_{0}}=\left\{\frac{X_{0}(1)+X_{0}(2)+X_{0}(3)+\ldots+X_{i}(n)}{N}\right\}, \\
Y_{i}=\left\{Y_{i}(1), Y_{i}(2), Y_{i}(3), \ldots, Y_{i}(n)\right\}= \\
\\
\left\{\frac{X_{i}(1)}{X_{i}}, \frac{X_{i}(2)}{\overline{X_{i}}}, \ldots, \frac{X_{i}(n)}{X_{i}}\right\}, \\
\overline{X_{i}}=\left\{\frac{X_{i}(1)+X_{i}(2)+X_{i}(3)+\ldots+X_{i}(n)}{N}\right\},
\end{gathered}
$$

The formula is shown in Eq. (6), where $\xi_{i}(k)-$ the correlation coefficient; $\zeta$ - the resolution coefficient, and its value is 0.5 .

$$
\begin{gathered}
\xi_{i}(k)=\left[\min _{i} \min _{k}\left|Y_{0}(k)-Y_{i}(k)\right|+\varsigma \max _{i} \max _{k}\left|Y_{0}(k)-Y_{i}(k)\right|\right] \times \\
{\left[\left|Y_{0}(k)-Y_{i}(k)\right|+\varsigma \max _{i} \max _{k}\left|Y_{0}(k)-Y_{i}(k)\right|\right]^{-1}}
\end{gathered}
$$

The relational degree $\gamma_{i}$ is shown in Eq. (7).

$$
\gamma_{i}=\frac{1}{N} \sum_{k=1}^{n} \xi_{i}(k) \text {. }
$$

The reference and the comparison consequences are extracted from Table 2 corresponding to the SBS-modified bitumen and from Table 3 corresponding to the PE-modified bitumen. The data extracted is shown in Table 4 .

The data in Table 3 should be substituted into the Equations (2)-(5), The grey relational degrees of two factors on the reference item of two kinds of modified bitumen can be calculated as shown in Table 5 .

It can be seen that the temperature and time influence the cohesive strength of bitumen similarly. The data shows that the relational degree of temperature is slightly higher than the correlation of ageing time, which shows that the temperature influences the bitumen cohesive strength slightly higher than the ageing time.

\subsection{Discussion of the active mechanisms of ageing}

How ageing effect influences bituminous binder low-temperature cohesive strength should be analysed from the angle of bitumen component characteristics. Local and foreign studies have shown that bitumen components can be analysed by using the four- or five-component method. The four-component method is more commonly used than the five-component approach. In the four-component method, the bituminous binder is a mixture of four components, namely asphaltene, glial, aromatic phenols and saturated phenols. The components of the SBS-modified bitumen are separated by using the part separation technique by the four-component analysis method. The separation results are shown in Figure 11. In the fourcomponent bitumen, the asphaltene and glial contents are relatively large and significantly affect the high-temperature properties of bitumen. Aromatic phenols and saturated phenols are relatively little but exert significant effects on the low-temperature properties of bitumen.

The light components (e.g., aromatic phenols and saturated phenols) were volatilized during the bitumen ageing process. A significant relationship was found between the volatile content and ageing time, i.e., a longer ageing time corresponds to the increased volatilization of light components. The percentage content of asphaltene and glial in bitumen increased after the light components volatilized and then exhibited adverse effects on bitumen low-temperature cohesive strength after the light components were reduced. The test results show that bitumen cohesive strength have different degrees of reduction at temperature conditions of $-10{ }^{\circ} \mathrm{C},-15{ }^{\circ} \mathrm{C},-20^{\circ} \mathrm{C}$ and

Table 4. The reference and comparison sequences of modified bitumen

\begin{tabular}{|c|c|c|c|c|c|}
\hline \multicolumn{7}{|c|}{ Styrene-Butadiene-Styrene } \\
\hline Cohesive strength & 0.97 & 1.2 & 1.23 & 1.85 & 2.12 \\
\hline Ageing time, $\mathrm{h}$ & 0 & 6 & 18 & 24 & 48 \\
\hline Temperature, ${ }^{\circ} \mathrm{C}$ & -25 & -20 & -15 & -10 & -5 \\
\hline \multicolumn{7}{|c|}{ Polyethylene } \\
\hline Cohesive strength & 0.89 & 1.13 & 0.99 & 1.95 & 2.15 \\
\hline Ageing time, $\mathrm{h}$ & 0 & 6 & 18 & 24 & 48 \\
\hline Temperature, ${ }^{\circ} \mathrm{C}$ & -25 & -20 & -15 & -10 & -5 \\
\hline
\end{tabular}

Table 5. The grey relational degree of factors on the reference item of modified bitumen

\begin{tabular}{|c|c|c|}
\hline \multirow{2}{*}{ Factor } & \multicolumn{2}{|c|}{ Modified bitumen } \\
\cline { 2 - 3 } & $\begin{array}{c}\text { Styrene-Butadiene- } \\
\text { Styrene }\end{array}$ & Polyethylene \\
\hline Ageing time, $\mathrm{h}$ & 0.630378854 & 0.686360238 \\
\hline Temperature, ${ }^{\circ} \mathrm{C}$ & 0.638492806 & 0.707009023 \\
\hline
\end{tabular}



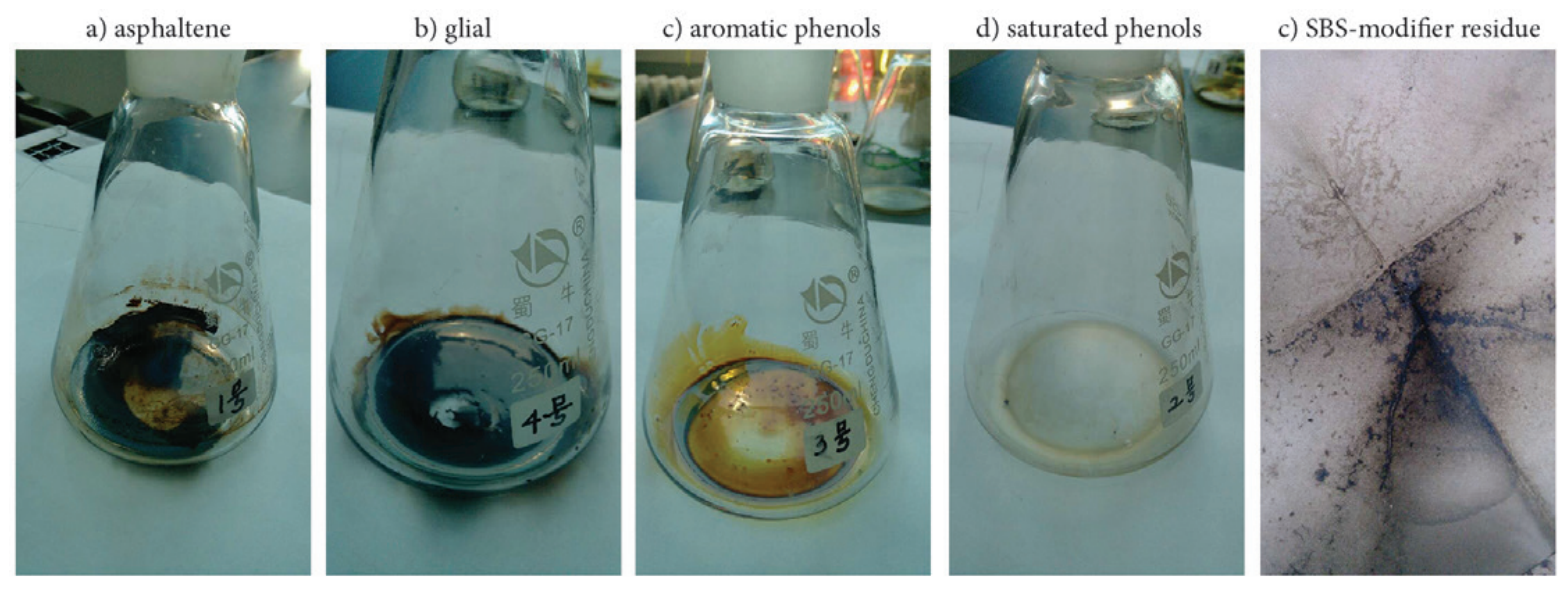

Figure 11. Bitumen four-component separation results

$-25{ }^{\circ} \mathrm{C}$ in addition to $-5{ }^{\circ} \mathrm{C}$. At $-5{ }^{\circ} \mathrm{C}$, the bitumen cohesive strength exhibited an increasing trend at bitumen mild freezing conditions. The hardness of the bitumen increased because of the increased bitumen viscosity after ageing and because the low-temperature environmental effect is not clear.

The influence mechanism of the ageing effect at the time when the bitumen low-temperature cohesive strength peaks should be analysed from the angle of the bitumen four-component glass transfer temperature. Each of the four substances has its glass transfer temperature. Researchers have already tested the glass transition temperatures of the four components by using the differential scanning calorimeter (DSC). The glass transition temperature of the four components was obtained by the differential scanning curves of the four components. The test results showed that the glass transition temperatures of saturated phenols, aromatic phenols, and asphaltene were $-38.72{ }^{\circ} \mathrm{C},-33.63{ }^{\circ} \mathrm{C}$ and $58.12^{\circ} \mathrm{C}$, respectively. The glass transition temperature of glial was higher than that of asphaltene. Further analysis based on the apparent glass transition temperature of each part shows that the bitumen macro-brittle transition temperature was definitely affected by the different proportions of the four components, i.e., the time when the bitumen low-temperature cohesive strength peaks.

With the light components evaporation in the bitumen ageing process, the percentage of aromatic phenols and saturated phenols decreased and the percentage of asphaltene and glial increased. Therefore, the material content with the high glass transition temperature increased, and the material content with the low glass transition temperature decreased. This situation will increase bitumen macro-brittle temperature. By the above analysis, the results of this study showed that the macro-brittle temperature of the original bitumen and that of the bitumen after ageing for $6 \mathrm{~h}$ is $-15^{\circ} \mathrm{C}$ and that for bitumen after ageing for $18 \mathrm{~h}$ and $24 \mathrm{~h}$ was $-10^{\circ} \mathrm{C}$. In conclusion, no peak attenuation of the bitumen occurs after ageing for $48 \mathrm{~h}$ and bitumen macro-brittle temperatures higher than $-10^{\circ} \mathrm{C}$ were reasonable.

\section{Conclusions}

This study was based on the film ageing test, which aged the SBS- and PE-modified bitumen at different periods. A quantitative test for the low-temperature cohesive strength of the above mentioned bitumen at different temperature conditions was designed and conducted. The following conclusions were drawn on the basis of the findings of this study.

1. The low-temperature cohesive strength of the two types of polymer-modified bitumen attenuated after ageing in the temperature range of $-10{ }^{\circ} \mathrm{C}$ to $-25^{\circ} \mathrm{C}$. Specifically, after ageing for $48 \mathrm{~h}$, the mean attenuation of the two types of bitumen low-temperature cohesive strength was $24.35 \%$ at $-10{ }^{\circ} \mathrm{C}, 65.05 \%$ at $-15{ }^{\circ} \mathrm{C}, 63.4 \%$ at $-20{ }^{\circ} \mathrm{C}$ and $62.95 \%$ at $-25{ }^{\circ} \mathrm{C}$.

2. At $-5^{\circ} \mathrm{C}$, the bitumen cohesive strength manifests an increasing trend at the bitumen mild freezing condition and its hardness increases because of the increased bitumen viscosity after ageing and the unclear low-temperature environmental effect.

3. The low-temperature cohesive strength of the two types of bitumen shows differences at different temperature conditions, but the decay law of the two low-temperature cohesive strength is the same. The low-temperature cohesive strength of the original bitumen and the modified bitumen after ageing for $6 \mathrm{~h}$ peaked at $-15{ }^{\circ} \mathrm{C}$ and $-10{ }^{\circ} \mathrm{C}$ after ageing for $18 \mathrm{~h}$ and $24 \mathrm{~h}$. The low-temperature cohesive strength of the two types of bitumen presented a single-trend attenuation with no peaks after ageing for $48 \mathrm{~h}$.

4. With reference to the grey system incidence theory, the reference consequences and comparison consequences extracted from the raw data are analysed and calculated. It is found that both the temperature and the ageing time has great influence on the adhesive strength of the modified bitumen thick oil film. The data shows that the effect of temperature on the tensile strength of bitumen is slightly greater 
than the effect of ageing time. However, in the study of bitumen low-temperature tensile strength, both two factors should be taken seriously.

5. While the light components evaporated in the bitumen ageing process, the percentage of asphaltene and glial in the bitumen increased, thus prompting the bitumen to produce brittle characteristics and adversely affecting the bitumen low-temperature cohesive strength in the temperature range of $-10{ }^{\circ} \mathrm{C}$ to $-25^{\circ} \mathrm{C}$. At the same time, owing to the increased percentage content of the material (asphaltene and glial) with the high glass transition temperature and decreased percentage content of the material (aromatic phenols and saturated phenols) with the low glass transition temperature, the bitumen macrobrittle transition temperature increased such that the embrittlement reaction of the bitumen binder occurred at a relatively high temperature. This phenomenon resulted in the severe attenuation of the low-temperature cohesive strength and affected the low-temperature anti-cracking of the asphalt mixture.

\section{Acknowledgements}

We express our gratitude for the funding provided by the National Natural Science Foundation of China (51508223), China Postdoctoral Science Foundation (2014M561299), Jilin Province Natural Science Foundation of China (20160101267JC), Jilin Province Traffic Science and Technology Development Plan of China (2014-1-7). We would also like to thank the Laboratory of Road Building Materials, Jilin University, which provided advanced experimental equipment for this research. We also acknowledge the hard work of the research group to complete this research.

\section{References}

Arifuzzaman, M., \& Hassan, M. R. 2014. Moisture damage prediction of polymer modified asphalt binder using support vector regression. Journal of Computational and Theoretical Nanoscience, 11, 2221-2227. https://doi.org/10.1166/jctn.2014.3630

Cerni, G., Cardone, F., \& Colagrande, S. (2011). Lowtemperature tensile behaviour of asphalt binders: application of loading time-temperature-conditioning time superposition principle. Construction And Building Materials, 25(4), 2133-2145.

https://doi.org/10.1016/j.conbuildmat.2010.11.018

Falchetto, A. C., Moon, K. H., \& Wistuba, M. P. (2016). Investigation on the development of asphalt mixture limit criteria for low-temperature cracking. Transportation Research Record, 2574, 83-91. https://doi.org/10.3141/2574-09

Fang, C. Q., Hu, J. B., \& Zhou, S. S. (2011). Comparative study of asphalts modified by packaging waste EPS and waste PE. Polymer-Plastics Technology and Engineering, 50(2), 220-224. https://doi.org/10.1080/03602559.2010.531436

Fang, C. Q., Zhang, M. R., \& Zhang, Z. P. (2009). UV-Aging resistance of packaging waste PE modified asphalts. PolymerPlastics Technology and Engineering, 48(9), 945-949. https://doi.org/10.1080/03602550902995059

Fang, C. Q., Li, T. H., Zhang, Z. P. (2008). Combined modifica- tion of asphalt by waste PE and rubber. Polymer Composites, 29(10), 1183-1187. https://doi.org/10.1002/pc.20424

Forough, S. A., Nejad, F.M., \& Khodaii, A. (2017). Predicting the tensile relaxation modulus of asphalt mixes based on the mix design and environmental factors. International Journal of Pavement Engineering, 18(7), 633-644.

https://doi.org/10.1080/10298436.2015.1121776

Gao, G.T., Zhang, Y., \& Zhang, Y. X. (2002). Improved storage stability of LDPE/SBS blends modified asphalts. Polymerse Polymer Composites, 10(3), 229-236.

Guo, M., Tan, Y., \& Zhou, S. (2014). Multiscale test research on interfacial adhesion property of Cold Mix Asphalt. Construction and Building Materials, 68, 769-776.

https://doi.org/10.1016/j.conbuildmat.2014.06.031

Hampl, R., Vacin, O., \& Jasso, M. (2015). Modeling of tensile creep and recovery of polymer modified asphalt binders at low temperatures. Applied Rheology, 25(3), 54-61.

Hamzah, M. O., Yee, T. S., \& Golchin, B. (2017). Use of imaging technique and direct tensile test to evaluate moisture damage properties of warm mix asphalt using response surface method. Construction And Building Materials, 132, 323-334. https://doi.org/10.1016/j.conbuildmat.2016.11.092

Jahanbakahsh, H., Karimi, M. M., \& Tabatabaee, N. (2017). Experimental and numerical investigation of low-temperature performance of modified asphalt binders and mixtures. Road Materials And Pavement Design, 18(6), 1353-1374.

https://doi.org/10.1080/14680629.2016.1220864

Kim, H., Lee, S. J., \& Amirkhanian, S. N. (2013). Quantification of oxidative aging of polymer-modified asphalt mixes made with warm mix technologies. Journal of Materials in Civil Engineering, 25(1), 1-8.

https://doi.org/10.1061/(ASCE)MT.1943-5533.0000479

Krcmarik, M., Varma, S., \& Kutay, M. E. (2016). Development of predictive models for low-temperature indirect tensile strength of asphalt mixtures. Journal of Materials in Civil Engineering, 28(11). https://doi.org/10.1061/(ASCE)MT.1943-5533.0001655

Li, Y. T., Li, L. F., \& Zhang, Y. (2010). Improving the aging resistance of Styrene-Butadiene-Styrene Tri-Block Copolymer and Application in Polymer-Modified Asphalt. Journal of Applied Polymer Science, 116(2), 754-761.

Lopes, M., Zhao, D., \& Chailleux, E. (2014). Characterisation of ageing processes on the Asphalt Mixture Surface. Road Materials and Pavement Design, 15(3), 477-487. https://doi.org/10.1080/14680629.2014.922656

Lv, D., Zheng, C. F., \& Qin, Y. (2014). Analysing the effects of the mesoscopic characteristics of mineral powder fillers on the cohesive strength of asphalt mortars at low temperatures. Construction and Building Materials, 65, 330-337. https://doi.org/10.1016/j.conbuildmat.2014.04.123

Mills-Beale, J., You, Z. P., \& Fini, E. (2014). Aging influence on rheology properties of petroleum-based asphalt modified with biobinder. Journal of Materials in Civil Engineering, 26(2), 358366. https://doi.org/10.1061/(ASCE)MT.1943-5533.0000712

Modarres, A. 2013. Investigating the toughness and fatigue behavior of conventional and SBS modified asphalt mixes. Construction and Building Materials, 47, 218-222. https://doi.org/10.1016/j.conbuildmat.2013.05.044

Nejad, F. M., Azarhoosh, A., \& Hamedi, G. H. (2014). Effect of high density polyethylene on the fatigue and rutting performance of hot mix asphalt - a laboratory study. Road Materials and Pavement Design, 15(3), 746-756. https://doi.org/10.1080/14680629.2013.876443

Wang, F. L., Long, J., \& Shen, B. X. (2014). A Study of the regen- 
erating effects of recycling agents on aged asphalts. Petroleum Science and Technology, 32(10), 1160-1167.

https://doi.org/10.1080/10916466.2011.616566

Wang, S. F., Zhang, Y., \& Zhang, Y. X. (2003). SBS/Carbon black compounds give asphalts with improved high-temperature storage stability. Polymers \& Polymer Composites, 11(6), 477-485.

Wang, Y. P., Liu, D. J., \& Li, Y. F. (2006). Preparation and properties of asphalts modified with SBS/organobentonite Blends. Polymerse Polymer Composites, 14(4), 403-411.

Yeon, K. S., Kim, S., \& Lee, H. J. (2014). Low temperature tensile characteristics of Warm-Mix Asphalt Mixtures. Journal of Testing and Evaluation, 42(4), 903-911. https://doi.org/10.1520/JTE20120364

Yut, I., \& Zofka, A. (2014). Correlation between rheology and chemical composition of aged polymer-modified asphalts. Construction and Building Materials, 62, 109-117. https://doi.org/10.1016/j.conbuildmat.2014.03.043

Zhao, Y. L., Gu, F., \& Xu, J. (2010). Analysis of aging mechanism of SBS Polymer Modified Asphalt Based on Fourier Transform Infrared Spectrum. Journal of Wuhan University of Technology-Materials Science Edition, 25(6), 1047-1052. https://doi.org/10.1007/s11595-010-0147-3

Zheng, C. F., Zhao, D. J., \& Xiang, N. L. (2012). Mechanism of low-temperature adhesion failure in asphalt mixtures with dense-suspension and void-skeleton structures. Construction and Building Materials, 36, 711-718.

https://doi.org/10.1016/j.conbuildmat.2012.06.058

Zheng, C. F., Chen, C. J., Zhao, D. J. (2014). Test technology study on mesoscopic shear strength of mineral aggregate contact surface. Journal of Materials in Civil Engineering, 26(1), 9098. https://doi.org/10.1061/(ASCE)MT.1943-5533.0000767

Zheng, C. F., Zhao, D. J., \& Chen, C. J. (2013). Quantitative test technology study on the mesoscopic strength parameters of the mineral aggregate contact surface of bituminous-stabilized Macadam. Construction and Building Materials, 40, 622-631. https://doi.org/10.1016/j.conbuildmat.2012.11.059

Zhu, Q., Zhou, C., \& Wang, S. Y. (2014). The regeneration of aged SBS modified asphalt via Re-reticulating SBS particles under Gamma Irradiation. Petroleum Science and Technology, 32(12), 1490-1496. https://doi.org/10.1080/10916466.2011.654303 